Int. J. Electrochem. Sci., 11 (2016) $4779-4793$

\title{
Preparation and Evaluation of a Stable Solid State Ion Selective Electrode of Polypyrrole/Electrochemically Reduced Graphene/Glassy Carbon Substrate for Soil Nitrate Sensing
}

\author{
Pu Pan ${ }^{1,3}$, Zhang Miao ${ }^{1, *}$, Li Yanhua ${ }^{1}$, Zhang Linan ${ }^{2}$, Ren Haiyan ${ }^{1}$, Kong Pan $^{2}$, Pan Linpei $^{2}$ \\ ${ }^{1}$ Key Laboratory on Modern Precision Agriculture System Integration Research of Ministry of \\ Education, China Agricultural University, Beijing 100083, China \\ ${ }^{2}$ Key Lab of Agricultural Information Acquisition Technology, China Agricultural University, Beijing \\ 100083, China \\ ${ }^{3}$ Northwest Agriculture and Forestry University, Yang ling 712100, China \\ *E-mail: zhangmiao@ cau.edu.cn
}

doi: $10.20964 / 2016.06 .7$

Received: 15 February 2016 / Accepted: 2 April 2016 / Published: 4 May 2016

In this study, a stable solid state sensor was developed for soil nitrate detection, which was based on the molecular imprinting principle using polypyrrole doped with nitrate $\left(\mathrm{PPy}-\mathrm{NO}_{3}^{-}\right)$as the ion-selective membrane. Firstly, a theoretical analysis was conducted to confirm that a water layer formation between ion selective membrane and substrate was the key reason to response potential drift then a graphene layer was introduced as a hydrophobic solid contact layer by electrochemical reduction of graphene oxide onto the surface of glass carbon electrode (GCE). Finally, a PPy- $\mathrm{NO}_{3}^{-}$film was modified on the GR layer by a pulsed electro-polymerization technique and the novel nitrate sensor was finished. The physical and electrochemical properties of obtained sensor were detailed by different characterization methods then a real soil detection was carried out to evaluate the sensor performance in practical application. It was found that the graphene layer could restrain the water layer formation and promote ion-to-electron transition effectively, which would enhance the output stability and response rate significantly. For the sensor, many expected performances were presented such as higher stability, sensitivity and selectivity, etc., which was indicated by a negligible potential drift $(0.67 \pm 0.05$ $\left.\mathrm{mV} \cdot \mathrm{h}^{-1}\right)$, higher Nernstian slope $\left(56.2 \pm 0.2 \mathrm{mV} \cdot \mathrm{decade}^{-1}\right)$, wide linear range $\left(10^{-5}-10^{-1} \mathrm{M}\right)$, satisfied detection limit $\left(10^{-5.2 \pm 0.1} \mathrm{M}\right)$ and a shorter response time $(\leq 15 \mathrm{~s})$. In real soil detection, the satisfactory results support its availability in agriculture application.

Keywords: Nitrate sensor; molecular imprinting technique; polypyrrole; graphene

\section{FULL TEXT}


(C) 2016 The Authors. Published by ESG (www.electrochemsci.org). This article is an open access article distributed under the terms and conditions of the Creative Commons Attribution license (http://creativecommons.org/licenses/by/4.0/). 